\title{
Caracterização da atividade pesqueira desenvolvida em comunidades rurais do nordeste paraense - Amazônia - Brasil
}

\author{
Characterization of the fishing developed in rural communities on the northeast \\ state of Para - Amazon - Brazil
}

\author{
Tiago Perereira Brito $\left.{ }^{1 *}\right)$ \\ Léa Carolina de Oliveira Costa²
}

\section{Resumo}

O presente estudo descreve os aspectos socieoeconômicos e a atividade de pesca desenvolvida pelas comunidades de Igarapé Açu (Capitão Poço) e São José (Ourém), no nordeste paraense. Os dados foram coletados a partir de 55 entrevistas semiestruturadas realizadas com pessoas que desenvolviam a pesca na região. A pesca foi desenvolvida predominantemente por homens, tanto jovens como adultos. A maioria deles foi natural do próprio estado, com tempo médio de moradia nas comunidades acima de 35 anos. O grau de instrução escolar variou desde pessoas que nunca frequentaram a escola até pessoas que ingressaram no ensino superior, mas não o concluíram. A pesca não representou a principal fonte de renda familiar dos entrevistados, sendo praticada geralmente para subsistência e o excedente do pescado era usado como moeda de troca, refletindo que as comunidades foram prioritariamente agrícolas e não de tradição pesqueira. $\mathrm{Na}$ região, foi comum o uso de redes de emalhe, de arrasto e de tapagem, tarrafa, linha de mão, espinhel, matapi e com destaque para a pesca de mergulho. As frequências de viagens registradas eram diárias, semanais ou mensais, para captura de espécies para o consumo, bem como espécies aquariofilistas.

Palavras chave: Arte de pesca; Pará; pesca artesanal; pescador; pesca ornamental.

\section{Abstract}

This study describes socioeconomic and technology aspects of fishing on Igarapé Açu (Capitão Poço) and São José (Ourém) communities in northeastern Pará state. The datas were collected through 55 semi-structured interviews with local fishermen. The fishing was carried mainly by men, young and adults. Most of them were from state itself, with average time of residence in the community over 35 years. The educational level ranged from people who have never attended school to people who entered higher education school, but did not finish. The fishing was not the main source of family income of people interviewed generally practiced for subsistence. Surplus fish was used as carried barter, reflecting the communities were primarily agricultural and non-fishing tradition. In the region was usual to use driftnet, trawl net, tide canals net,

I Me., Oceanógrafo; Professor do Instituto Federal de Eduação, Ciência e Tecnologia do Pará - IFPA; Endereço: Rodovia BR 316,KM 62, Saudade, CEP 68740-970, Castanhal-PA,Brasil;E-mail:britotp@yahoo.com.br .(*)Autor para correspondência.

2 Ma., Aquicultura; Professora do Instituro Federal de Educação, Ciência e Tecnologia do Pará - IFPA; Endereço: Rodovia

BR 316, KM 63, s/n, Titanlândia, CEP 6874I-740, Castanhal-PA, Brasil; E-mail: leacarolinacosta@yahoo.com.br Recebido para publicação em 22/II/2015 e aceito em 01/08/2018

\begin{tabular}{llllll}
\hline Ambiência & Guarapuava (PR) & v.l5 n.2 & p. $475-498$ & Maio/Ago 2019 & ISSN 1808 - 025I
\end{tabular}


casting net, fish hook and line, longline, basket trap, and especially fishing of diving. The fishing was carried with frequency of daily, weekly or monthly trips being made to capture species for consumption, as well as species aquarist.

Key words: Fisherman; fishing gear; artisanal fishing; ornamental fishing; Pará.

\section{Introdução}

A pesca na Amazônia tem se destacado pelo número de espécies capturadas, pelo volume de recurso explotado e pela dependência que a população local apresenta com esta atividade (BARTHEM; FABRÉ, 2003; RUFFINO et al., 2005, 2006). Ela contribui com 24,4\% da pesca brasileira, enquanto a pesca marinha representa 16,2\%, e a pesca continental, 58,9\% (IBAMA, 2008).

$\mathrm{Na}$ região, a atividade pesqueira tem demonstrado grande diversificação, sendo caracterizada por diferentes tipos de pescarias: pesca de subsistência, realizada por grupos familiares ou em sistema de parceria que utilizam estruturas de porte limitado; pesca esportiva e de lazer, realizada principalmente em ambientes límnicos de água preta; pesca ornamental, voltada principalmente para o mercado aquariofilista internacional; pesca desenvolvida em reservatórios, praticada em lagos das hidroelétricas de Tucuruí (PA) e Balbina (AM); pesca comercial monoespecífica, direcionadas principalmente à captura de bagres para exportação; e pesca comercial multiespecífica, destinada ao abastecimento dos centros urbanos regionais (FREITAS; RIVAS, 2006).

No estado do Pará, a pesca tem sido desenvolvida em diversos municípios, seja em águas límnicas, salobras e/ou marinhas, situadas no interior de lagos, rios, zona costeira e áreas mais afastadas da costa. $\mathrm{O}$ estado é considerado o segundo maior produtor de recursos pesqueiros do Brasil, sendo que a produção de pescado oriunda da pesca artesanal de águas interiores é a maior do país, representando cerca de 28,64\% da produção nacional (IBAMA, 2008).

A pesca artesanal, no estado, tem adotado embarcações de pequeno a médio porte, propulsionadas através do uso de remos, velas e/ou motores de baixa propulsão para se deslocarem aos pesqueiros situados em áreas próximas ou mesmo afastadas da comunidade. Os pescadores comumente utilizam petrechos de pesca mais simples, como matapis. linhas de mão, espinheis, tarrafas, redes de emalhe e arrasto, petrechos estes, geralmente, adquiridos no comércio da região ou que podem ser elaborados pelos próprios pescadores (SANTOS, 2005; SILVA et al., 2007; BRITO; VIANA, 2011; BRITO et al., 2015a; NOGUEIRA et al., 2015; RAMOS et al., 2015; BRITO et al., 2016a).

De forma a contribuir com informações sobre a pesca realizada no estado do Pará, o presente estudo pretende descrever os aspectos socioeconômicos e a atividade de pesca desenvolvida nas comunidades rurais de Igarapé Açu (município de Capitão Poço) e São José (município de Ourém), no nordeste do estado.

\section{Material e Métodos}

\section{Área de estudo}

O estudo foi realizado em duas comunidades localizadas na microrregião do Guamá,inseridas na mesorregião do nordeste paraense (Mapa 1). A vila ou comunidade de Igarapé Açu pertence ao município de Capitão Poço que compreende uma área de aproximadamente 2.899,53 km² e uma 
população de 50.774 habitantes. A comunidade de São José pertence ao município de Ourém, que compreende $602,57 \mathrm{~km}^{2}$ de área e cerca de 16.188 habitantes (IBGE, 2010). A região apresenta um clima que pode ser considerado como quente e úmido, com uma estação de menor precipitação entre os meses de junho e novembro e, um período de maior precipitação, com fortes chuvas concentradas entre os meses de dezembro e maio, sendo a pluviosidade média anual entre 2.500 e $3.000 \mathrm{~mm}$ e a umidade relativa do ar entre 80 e 91\% (MARTORANO et al., 1993).

\section{Mapa 1 - Localização dos municípios de Ourém e Capitão Poço no nordeste paraense.}

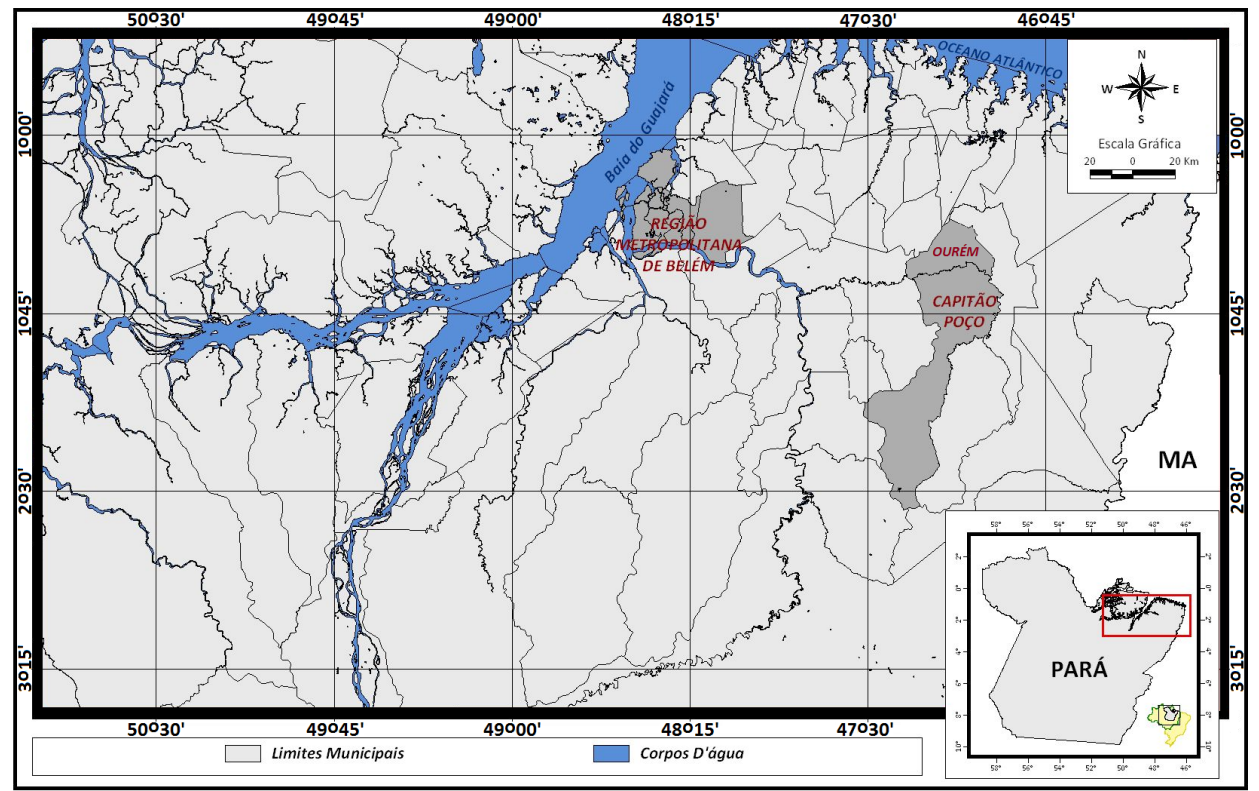

Fonte: Autores (2015).

\section{Coleta e processamento de dados}

A realização de entrevistas tem sido um método muito adotado para se compreender os aspectos sociais e econômicos dos entrevistados (SILVA et al., 2007; OLIVEIRA et al., 2015; BRITO et al., 2018), sobre as atividades de sustento e renda que desenvolvem (SOUZA, 2004; BRITO et al., 2015a; NOGUEIRA et al., 2015; RAMOS et al., 2015; BRITO et al. 2017), sobre aspectos etnoecológico da biota e sua relação com a atividade produtiva (BRITO, 2012; BRITO et al., 2015b; BRITO et al., 2016a), sobre o seu consumo alimentar (BRITO et al., 2016b) e sobre a percepção dos aspectos do ambiente que os rodeiam (BRITO et al., 2015c).

Por meio de entrevista é possível se obter dados a respeito dos mais variados temas da compreensão dos entrevistados, permitindo, também, se aprofundar em determinados assuntos desejados (LUDKE; ANDRÉ, 1986; CRUZ NETO, 1994; MERGULHÃO; VASAKI, 1998). Através dessa técnica, foi possível a coleta de dados socioeconômicos e da atividade pesqueira desenvolvida nas comunidades rurais de Igarapé Açu (município de Capitão Poço) e São José (município de Ourém), no nordeste do estado.

Um contato inicial, com a liderança da região, foi realizado para informar a respeito do estudo que seria desenvolvido. A partir dessa conversa, ocorreram as indicações das primeiras pessoas que trabalhavam com a pesca na área de estudo, adotando-se, posteriormente, o método 
de entrevista "bola de neve" (BAILEY, 1982), sendo solicitado, ao final de cada entrevista, que o entrevistado indicasse uma ou mais pessoas que também trabalhassem com a pesca para dar continuidade à pesquisa. Método esse, adotado em diversos estudos dessa natureza (BRITO et al., 2015b; BRITO et al., 2016a). Dessa forma, conseguiu-se um total de 55 entrevistas, sendo 24 delas realizadas na comunidade de Igarapé Açu (Capitão Poço) e, 31 na comunidade de São José (Ourém). As entrevistas semiestruturadas foram realizadas durante o mês de outubro de 2010, com duração média de 30 a 45 minutos cada.

Antes de serem iniciadas as entrevistas, os pesquisadores realizavam uma conversa prévia com o intuito de informar a respeito da pesquisa e perceber se o possível entrevistado teria disponibilidade para fornecer as informações necessárias. Percebendo o interesse do pescador, os entrevistadores discorriam para seu informante os objetivos do estudo e solicitavam sua participação na pesquisa, comunicando que seria garantido o anonimato dos informantes e que as informações fornecidas seriam apenas para fins acadêmicos e científicos.

Durante as entrevistas, buscou-se obter informações sobre os aspectos sociais e econômicos, bem como sobre as características da atividade de pesca desenvolvida na região. As perguntas contidas no roteiro de entrevista foram formuladas de acordo com os objetivos do estudo e, em conformidade com os dados levantados na literatura (SOUZA, 2004; SCHALLENBERGER, 2010). O roteiro semiestruturado elaborado compreendia questões referentes ao gênero, idade, naturalidade, tempo de moradia na região, grau de instrução escolar, quantidade de filhos e moradores na residência, renda familiar, atividade principal e secundária de renda, descrição da arte de pesca, espécies capturadas, tipo de embarcação utilizada, tempo gasto de deslocamento até o pesqueiro, tempo gasto pescando, dentre outros dados relevantes e necessários para a caracterização da atividade de pesca na região.

Ao final de cada entrevista realizada, os pesquisadores informavam aos entrevistados sobre o Termo de Autorização Livre e Esclarecida, no qual eles deveriam assinar, declarando que estavam cientes de que foram esclarecidos quanto à pesquisa e que autorizavam sua participação nela.

Os dados foram coletados no âmbito do Projeto "Caracterização das atividades de pesca e aquicultura no nordeste paraense: uma prática de pesquisa e extensão" financiado pela Diretoria de Formulação de Políticas de Educação Profissional e Tecnológica da Secretaria de Educação Profissional e Tecnológica do Ministério da Educação (DPEPT/SETEC/MEC). Depois de coletados, os dados foram sistematizados em planilha no programa Microsoft Office Excel 2010 para avaliação descritiva, bem como cálculo de média e desvio padrão. $O$ teste não paramétrico do Qui-quadrado ( $\chi 2)$ foi utilizado para avaliar a similaridade das frequências de amostras independentes e o teste Mann-Whitney (teste U) para testar a similaridade de amostras independentes, utilizando, para isso, o programa BioEstat 5.0 (AYRES et al., 2007).

\section{Resultados e Discussão}

\section{Caracterização dos pescadores}

$\mathrm{Na}$ comunidade de Igarapé Açu (Capitão Poço), todos os entrevistados eram do gênero masculino ( $\mathrm{n}=24)$, enquanto para a comunidade de São José (Ourém), 90,3\% dos entrevistados eram homens $(n=28)$ e $9,7 \%$ mulheres $(n=3)$. Dessa forma, o gênero feminino apresentou baixa representatividade na atividade de pesca, apesar, da liderança da comunidade ser realizada por uma 
mulher, que desenvolve a atividade pesqueira e agrícola. Em relação ao gênero, a predominância de homens na atividade de pesca foi similar para as comunidades estudadas $\left(\chi^{2}=2,4566 ; p=0,1170\right)$.

A predominância de homens na captura do pescado tem sido comum em colônias de pescadores no estado do Pará. Nas colônias Z-1 (Soure-PA) (BRITO; VIANA, 2011), Z-21 (Viseu-PA) (OLIVEIRA et al,. 2015) e Z-30 (Marabá-PA) (NOGUEIRA et al., 2015) todos os pescadores entrevistados eram homens, enquanto, para as colônias Z-7 (Maracanã-PA) (BRITO; VIANA, 2011), Z-23 (Colares-PA) (BRITO et al., 2016a) e Z-8 (São João de Pirabas-PA) (BRITO et al., 2015a) as mulheres apresentavam pouca representatividade, apesar de participarem da atividade de pesca.

Em comunidades pesqueiras e/ou agrícolas é comum a divisão de trabalho por gênero, onde os homens ficam encarregados dos trabalhos extrativistas e de produção, enquanto, as mulheres são responsáveis pelos trabalhos mais domiciliares. Essa divisão do trabalho em comunidades pesqueiras do litoral paraense foi registrada por Maneschy (1995).

Essa realidade também é comum para outros estados brasileiros, conforme registrado em seis comunidades pesqueiras do Vale da Ribeira e litoral sul do estado de São Paulo (RAMIRES et al., 2012) e em sete macro regiões de pesca do estado do Rio Grande do Sul (GARCEZ; SÁNCHEZ-BOTERO, 2005). Para Di Ciommo (1990, 1999), o trabalho masculino está, em grande parte, vinculado socialmente ao setor de produção de bens e serviços dentro da sociedade, enquanto, o papel da mulher culturalmente está vinculado à responsabilidade no âmbito familiar.

Essas relações de gênero apresentam grande importância sobre todos os aspectos dentro da comunidade, tanto no que se refere ao papel que cada indivíduo pode desenvolver dentro do setor produtivo, como qual função desempenha no âmbito social e familiar (VERDEJO, 2010). Para Nogueira (2012), a mulher desempenha uma função essencial para o modo de produção familiar, sendo responsável por estruturar o ambiente, possibilitando o desempenho da mão-deobra masculina no sistema de produção que possa garantir sustento e renda à família. $\mathrm{O}$ modo de divisão sócio-sexual do trabalho existe na esfera da família patriarcal como no mundo produtivo, baseando-se na associação entre a geração de renda e a produção.

Maneschy (1995) e Di Ciommo (2007) registraram que as mulheres também se envolvem com a pesca, mas seu trabalho tem sido pouco valorizado socialmente. Elas realizam a pesca, mesmo que esta atividade ainda seja considerada tradicionalmente masculina. No entanto, podem realizar atividades de extrativistas não realizadas por homens, como a extração de mariscos, podendo, também, ficar encarregadas da limpeza do pescado, tanto para o consumo familiar, quanto para agregar certo valor ao produto a ser comercializado; bem como podem ficar encarregadas no conserto dos artefatos de pesca dos companheiros, uma tarefa necessária para a manutenção da produção do setor pesqueiro.

$\mathrm{Na}$ comunidade de Igarapé Açu (Capitão Poço), a idade dos entrevistados variou de 16 a 74 anos (média de 41,2 \pm 16,4 anos), enquanto na comunidade de São José (Ourém) variou de 21 a 73 anos (média 41,6 \pm 14,8 anos), merecendo destaque para as faixas etárias entre 21 e 30 anos e entre 41 e 50 anos para ambas as comunidades estudadas (Tabela 1). A frequência da faixa etária registrada para os pescadores foi similar em relação às comunidades estudadas $\left(\chi^{2}=3,4313 ; p=0,6338\right)$, não demonstrando uma diferença significativa entre elas.

Para as duas comunidades foram verificadas que mais de 32,0\% dos entrevistados estavam na faixa etária abaixo dos 31 anos de idade, podendo ser um indício da representatividade maior de pessoas jovens na atividade de pesca, ocasionadas pela renovação de mão de obra na região, 
com a inserção cada vez mais cedo de pessoas jovens nessa atividade. Em comunidades pesqueiras do litoral paraense e das ilhas no entorno de Belém, PA vem ocorrendo o contrário, onde tem se predominado pessoas com faixa etária maior (SANTOS, 2005; BRITO; VIANA, 2011; BRITO et al.,2015a; OLIVEIRA et al., 2015; BRITO et al., 2016a, SCHALLENBERGER, 2010), bem como para pescadores do Rio Grande do Sul (GARCEZ; SÁNCHEZ-BOTERO, 2005), onde a predominância de pessoas com idades inferiores aos 31 anos foi relativamente baixa.

\section{Tabela 1 - Faixa etária dos pescadores entrevistados.}

\begin{tabular}{ccccc}
\hline \multirow{2}{*}{$\begin{array}{c}\text { Faixa etária } \\
\text { (anos) }\end{array}$} & $\begin{array}{c}\text { Comunidade de Igarapé Açu } \\
\text { (Capitão Poço) }\end{array}$ & \multicolumn{2}{c}{$\begin{array}{c}\text { Comunidade de São José } \\
\text { (Ourém) }\end{array}$} \\
\cline { 2 - 5 } & $\begin{array}{c}\text { Quant. de } \\
\text { respostas (n) }\end{array}$ & Freq. Relativa(\%) & $\begin{array}{c}\text { Quant. de } \\
\text { respostas (n) }\end{array}$ & $\begin{array}{c}\text { Freq. Relativa } \\
(\%)\end{array}$ \\
\hline > 21 & 02 & 08,3 & 00 & 00,0 \\
21 a 30 & 06 & 25,0 & 10 & 32,3 \\
31 a 40 & 03 & 12,6 & 03 & 09,7 \\
41 a 50 & 06 & 25,0 & 09 & 29,0 \\
51 a 60 & 05 & 20,8 & 05 & 16,1 \\
> 60 & 02 & 08,3 & 04 & 12,9 \\
\hline Total & 24 & 100,0 & 31 & 100,0 \\
\hline
\end{tabular}

Fonte: Autores (2015).

O predomínio de indivíduos adultos, na faixa etária entre 31 e 60 anos, envolvido na atividade pesqueira, indica que os atores que desenvolvem a pesca, nas duas comunidades, refletem uma boa parcela de pessoas economicamente ativas e experientes trabalhando com a pesca. Além disso, representam trabalhadores que podem ser considerados chefes de família, que apresentam a pesca como uma atividade que possa garantir uma fonte de proteína animal à alimentação, bem como, que garanta a complementação da renda familiar. Isso se confirma, por grande parte dessas pessoas terem apresentado cônjuges e filhos, construindo, portanto, uma base familiar a qual sustentam. Essa realidade também tem sido comum para produtores rurais que desenvolvem a criação de peixes na região (BRITO et al., 2018) e para pescadores do município de Viseu (PA) (OLIVEIRA et al., 2015).

$\mathrm{Na}$ comunidade de Igarapé Açu (Capitão Poço), 25,0\% dos entrevistados se declararam solteiros, os demais apresentavam algum tipo de relação a dois, sendo que 8,3\% declaram estar namorando, 16,7\% estavam amasiados e, 50,0\% estavam em relação matrimonial. Para a comunidade de São José (Ourém), 32,3\% se declararam solteiros e 3,2\% viúvos, portanto, não apresentaram nenhum tipo de relação atual a dois. A relação conjugal foi registrada para os que se declararam amasiados $(38,7 \%)$ e casados $(25,8 \%)$.

O tipo de estado civil se mostrou diferente entre as comunidades estudadas $\left(\chi^{2}=64,1257 ; \mathrm{p}\right.$ $=0,0000)$, o que pode estar relacionado à presença de pessoas em uma relação de namoro apenas na comunidade de Igarapé Açu e, de pessoas viúvas apenas na comunidade de São José, a qual também apresentou um percentual menor de pessoas casadas e maior de pessoas amasiadas em relação à primeira comunidade.

Esse resultado foi similar ao encontrado para os pescadores que utilizavam matapis, redes emalhes e redes de tapagem na Ilha das Onças (Barcarena, PA), os quais, em sua maioria, 
apresentaram cônjuges, bem como para a maioria dos pescadores da Ilha do Combu (Belém, PA) (SCHALLENBERGER, 2010). Costa et al. (2013) e Brito et al. (2015c) também verificaram que, em comunidades do interior do estado, os moradores, por apresentarem a faixa etária mais elevada, em sua maioria, apresentavam algum tipo de relacionamento a dois.

Dados do IBGE (2010) indicam que 48\% da população paraense apresentam algum tipo relação conjugal. Em ambas as comunidades estudadas, mais de $64,0 \%$ das pessoas possuem algum tipo de relacionamento a dois (namoro, amasiado, casado). Isso pode estar relacionado ao modo de vida social e cultural dessas comunidades, associado à faixa etária dos pescadores, onde mais de $65 \%$ eram de pessoas acima de 30 anos, sendo esperado que, os mesmos, apresentassem algum tipo de relacionamento para essa faixa etária. Uma realidade comumente observada para pessoas que convivem em um meio rural.

Barreto (2004) observou um alto número de pessoas com relacionamento conjugal em comunidades agrícolas do Ceará, atribuindo isso, a um reflexo da vida mais tranquila e simples que as pessoas das comunidades do interior possuem, estabelencendo uma relação conjugal mais duradoura.

A quantidade de filhos dos pescadores da comunidade de Igarapé Açu (Capitão Poço) variou de nenhum até sete filhos, sendo a média de 2,6 2,8 filhos por entrevistado. A maioria declarou não possuir filhos (41,6\%), enquanto, 29,2\% possuíam de 2 a 3 filhos, 4,2\% de 4 a 5 e, 25,0\% acima de 5 filhos. Em relação à comunidade de São José (Ourém), a quantidade de filhos variou de nenhum a dez filhos. A maioria não apresentou filhos (38,8\%), enquanto, 16,1\% possuíam um único filho, 16,1\% de 2 a 3,16,1\% de 4 a 5 e, 12,9\% acima de 5 filhos, com média de 2,4 4 2,9 filhos por entrevistado.

A quantidade de filhos apresentada pelos entrevistados demonstrou ser similar entre as comunidades estudadas $\left(\chi^{2}=7,8175 ; p=0,0985\right)$, não demonstrando diferença significativa entre elas. Essa realidade está relacionada justamente aos tipos de relacionamentos desenvolvidos entre os membros da comunidade, através do convívio a dois, tem se construído um ambiente familiar, onde é comum a presença de filhos.

Para pescadores do município de São João de Pirabas (PA), a quantidade de filhos variou de nenhum até 11 filhos, sendo a média de 3,0 \pm 2,6 filhos por pescador (BRITO et al., 2015a). Para os produtores rurais com foco na produção de peixes em Capitão Poço (PA), os mesmos possuíam até seis, com média de 3,0 \pm 1,6 filhos por produtor (BRITO et al., 2018) e, para comunidades rurais dos municípios de Castanhal (PA), os piscicultores possuíam até cinco filhos (média 2,1 \pm 1,4 filhos por produtor) (SANTOS et al., 2014). Demonstrando que as médias de filhos registradas, nas comunidades estudadas, tratam-se de uma realidade encontrada para populações pesqueiras e de produção agrícola no estado do Pará. Essas pessoas podem servir de mão de obra para o processo de produção da região, favorecendo a inclusão de uma força de trabalho jovem nessas atividades.

$\mathrm{Na}$ comunidade de Igarapé Açu (Capitão Poço) pelo menos 91,7\% dos entrevistados eram paraenses $(n=22)$. A maioria nasceu no próprio município de Capitão Poço $(33,3 \%)$ e no município adjacente de Ourém $(25,0 \%)$, os restantes $(33,4 \%)$ eram oriundos de Igarapé Açu, Santa Luzia, Jacarequara, Augusto Correia e Bragança. Uma parcela dos pescadores (8,3\%) não informou sua naturalidade. Para a comunidade de São José (Ourém), pelos menos, 90,3\% dos entrevistados eram paraenses $(n=28)$, sendo a maioria nascida no próprio município de Ourém $(67,7 \%)$, como também oriundos dos municípios de Capitão Poço (6,5\%), Primavera (3,2\%), Santa Rosa (3,2\%) e 9,7\% se declararam apenas paraenses, não informando seu município de origem. Uma parcela $(9,7 \%)$ não informou sua naturalidade, provavelmente por não ser paraense. 
Portanto, a naturalidade dos entrevistados demonstrou ser dependente da comunidade estudada $\left(\chi^{2}=24,9333 ; p=0,0016\right)$, havendo, portanto, diferença entre elas.

$\mathrm{O}$ fato dos pescadores serem naturais da própria região onde moram, favorece que eles possuam uma compreensão maior da área onde habitam. Conhecimento este, obtido por meio de sua percepção sobre o meio que os rodeiam e, através da interação e troca de experiências entre os demais membros da comunidade onde moram ou nos locais onde exercem a atividade de pesca. Essa compreensão também é apontada por Oliveira et al. (2015) e Brito et al. (2015a) para pescadores naturais e residentes em colônias pesqueiras do litoral paraense. Costa et al. (2013) e Brito et al. (2015c) consideram que indivíduos residentes em sua região de origem possam ter uma melhor percepção e compreensão do ambiente em que vivem.

O tempo de moradia dos entrevistados na comunidade de Igarapé Açu (Capitão Poço) variou de 6 a 74 anos (média 35,46 $\pm 18,51$ anos). Este resultado é similar ao encontrado na comunidade de São José (Ourém), no qual o tempo de moradia na região variou de 5 a 68 anos (média 35,92 \pm 16,02 anos), demonstrando que os entrevistados apresentam um tempo de permanência elevado nas comunidades onde residem, sendo que boa parcela deles é natural das próprias comunidades estudadas, podendo apresentar uma maior compreensão sobre a região e locais onde possam realizar a pesca.

Brito et al. (2018) apontaram que o tempo de residência relativamente elevado de produtores rurais na região pode contribuir para que os mesmos tenham um conhecimento mais amplo da área estudada e da atividade produtiva que possa melhor se adequar a realidade e necessidade do local. Dessa forma, os pescadores, conhecendo melhor o ambiente onde residem e os locais onde exercem a pescaria, podem adequar ou aperfeiçoar as artes de pesca de acordo com a necessidade de cada pesqueiro da região.

A quantidade de pessoas morando em cada residência variou de apenas uma a até 10 pessoas, sendo a média, por moradia, de 4,6 \pm 2,0 pessoas para a comunidade de Igarapé Açu (Capitão Poço). Em relação à comunidade de São José (Ourém), o número de pessoas por moradia variou de uma a oito, com média de 4,2 $\pm 2,5$ pessoas.

As casas eram dos próprios entrevistados, exceto para dois deles, sendo um de cada comunidade estudada, os quais afirmaram morar em casas alugadas. Essa realidade se assemelha a encontrada em comunidades pesqueiras do litoral do estado, em que a média de pessoas, por moradia, variou entre 4 e 5 pessoas, sendo, em sua maioria, pescadores que possuíam casa própria (BRITO et al., 2015a; OLIVEIRA et al. 2015). Garcez e Sánchez-Botero (2005) também registraram a presença, em média, de 4 pessoas por moradia em comunidades de pescadores do estado do Rio Grande do Sul.

A quantidade de pessoas, por moradia, pode evidenciar a presença de núcleos familiares formados por cônjuges que sustentam seus descendentes, através do desenvolvimento de atividades agrícolas e pesqueiras, bem como, de jovens que desenvolvem a pesca e residem com seus pais de forma a contribuir com o sustento e a renda familiar, pois uma parcela desses jovens apresenta filhos, mas ainda não é totalmente independente por não possuir casa própria.

O grau de instrução escolar dos entrevistados da comunidade de Igarapé Açu (Capitão Poço) variou desde pescadores que nunca frequentaram a escola, não sabendo ler ou escrever $(20,8 \%)$ a pescadores que ingressaram no ensino superior, mas não o concluíram (12,6\%). Para a escolaridade o destaque é para pescadores com ensino fundamental incompleto que representam (50,0\%) dos entrevistados. Essa realidade também foi registrada para a comunidade de São José 
(Ourém), prevalecendo o ensino fundamento incompleto $(77,4 \%)$ como o grau de instrução da maioria dos entrevistados (Tabela 2), portanto, o grau de instrução escolar foi similar entre as comunidades estudadas $(\chi 2=7,2600 ; \mathrm{p}=0,2020)$.

\section{Tabela 2 - Grau de instrução escolar dos pescadores entrevistados.}

\begin{tabular}{ccccc}
\hline & \multicolumn{2}{c}{$\begin{array}{c}\text { Comunidade de Igarapé Açu } \\
\text { (Capitão Poço) }\end{array}$} & \multicolumn{2}{c}{$\begin{array}{c}\text { Comunidade de São José } \\
\text { (Ourém) }\end{array}$} \\
\cline { 2 - 5 } Instrução escolar & $\begin{array}{c}\text { Quant. de } \\
\text { respostas (n) }\end{array}$ & Freq. Relativa (\%) & $\begin{array}{c}\text { Quant. de } \\
\text { respostas (n) }\end{array}$ & $\begin{array}{c}\text { Freq. Relativa } \\
\text { (\%) }\end{array}$ \\
\hline $\begin{array}{c}\text { Sem instrução } \\
\text { Ens. Fund. } \\
\begin{array}{c}\text { Incompleto } \\
\text { Ens. Fund. }\end{array}\end{array}$ & 05 & 20,8 & 03 & 09,7 \\
$\begin{array}{c}\text { Completo } \\
\text { Ens. Médio }\end{array}$ & 12 & 50,0 & 24 & 77,4 \\
$\begin{array}{l}\text { Incompleto } \\
\text { Ens. Médio } \\
\text { Completo }\end{array}$ & 02 & 08,3 & 00 & 00,0 \\
$\begin{array}{c}\text { Ens. Sup. } \\
\text { Incompleto }\end{array}$ & 00 & 08,3 & 01 & 03,2 \\
\hline Total & 03 & 00,0 & 01 & 03,2 \\
\hline
\end{tabular}

Fonte: Autores (2015).

Os pescadores apresentaram um baixo nível de escolaridade, assim como os pescadores dos municípios de São João de Pirabas (BRITO et al., 2015a) e Viseu (OLIVEIRA et al., 2015), prevalecendo pessoas com ensino fundamental incompleto e iletrados. Dessa forma, essa realidade tem sido comum para comunidades pesqueiras do estado do Pará, bem como para pescadores de comunidades do Vale da Ribeira e litoral sul do estado de São Paulo (RAMIRES et al, 2012) e do Rio Grande do Sul (GARCEZ; SÁNCHEZ-BOTERO, 2005).

$\mathrm{O}$ acesso às instituições de ensino em centro rurais é um dos fatores que dificulta a frequência de jovens e crianças às escolas, pois têm seus locais de moradias distante delas, muitas vezes, não há meio de transporte regular para seu acesso. Soma-se a isso, o fato de que muitos dos alunos, que deveriam frequentar as escolas, estão contribuindo com as tarefas domiciliares e/ou de sustento familiar, não conseguindo conciliar essa jornada de trabalho com seus estudos. Dessa forma, muitos alunos acabam abandonando as escolas, antes de concluírem seus estudos, enquanto, outros acabam nem tendo a chance de ingressar nelas. Realidade enfrentada pelos pescadores das comunidades de Igarapé Açu (Capitão Poço) e São José (Ourém), bem como muitos produtores rurais (SANTOS et al., 2014; BRITO et al., 2018), pescadores (OLIVEIRA et al., 2015; BRITO et al., 2015a) e morados do interior do estado (COSTA et al, 2015; BRITO et al., 2015c).

A agricultura foi a principal atividade de sustento para $66,7 \%$ dos entrevistados da comunidade de Igarapé Açu (Capitão Poço), apenas 33,3\% deles tinham a pesca como a principal atividade de renda. Na comunidade de São José (Ourém) a pesca foi a atividade principal de renda e subsistência para apenas $16,3 \%$ dos entrevistados, os demais $(83,9 \%)$ apresentaram a agricultura 
como principal atividade de sustento familiar. Portanto, independentemente das comunidades estudas, a base de renda delas foi a agricultura familiar e não a pesca $\left(\chi^{2}=2,218 ; \mathrm{p}=0,1364\right)$.

A pesca, nessas comunidades, tem sido uma atividade secundária desenvolvida para subsistência, como forma de inserir proteína animal na dieta familiar e, como uma atividade de renda complementar, ao vender o excedente de pescado capturado e/ou utilizar o pescado como uma moeda de troca de mercadorias. Isso reflete que as comunidades foram prioritariamente de produção agrícola e não de tradição pesqueira. Ao contrário do registrado para os pescadores do litoral paraense, que apresentam a pesca como principal atividade de renda. No entanto, ela nem sempre é capaz de garantir o sustento total das famílias que dependem dela, as quais necessitam desenvolver atividades secundárias para complementação da renda familiar (SANTOS et al., 2005; BRITO; VIANA, 2011; OLIVEIRA et al., 2015; BRITO et al., 2015a).

O quantitativo baixo de pessoas que apresentam a pesca como atividade principal de renda, nas comunidades de Igarapé Açu (Capitão Poço) e São José (Ourém), pode ser consequência da falta da organização dos sujeitos, pois nenhum dos entrevistados esteve cadastrado em alguma associação ou colônia relacionada ao desenvolvimento da pesca. A inserção de uma organização social, relacionada à atividade pesqueira, poderia subsidiar os pescadores a terem maior representação social e política na região, assegurando, também, que os seus direitos, previstos em lei, possam ser garantidos.

A finalidade da organização social seria substituir as ações individuais por ações coletivas, proporcionando o fortalecimento da classe e dando condições para que os próprios pescadores se articulem e melhorem a produtividade, adotando um sistema de manejo da pesca local para que ela possa se desenvolver de forma sustentável. Portanto, a falta dessa organização pode contribuir para o enfraquecimento do desenvolvimento do setor pesqueiro nessas comunidades, favorecendo que a pesca não possa garantir renda e sustento das famílias que a praticam.

$\mathrm{Na}$ comunidade de Igarapé Açu (Capitão Poço) a renda mensal, para a maioria dos entrevistados (54,2\%), foi inferior a um salário mínimo, para 41,6\% foi de um a dois salários e, para 4,2\% foi de três a quatro salários. Para a comunidade de São José (Ourém) a renda mensal de 71,0\% dos entrevistados foi inferior a um salário e, de um a dois salários para $29,0 \%$. Portanto, a renda familiar não demonstrou diferença entre as comunidades estudadas $(\chi 2=2,5168 ; \mathrm{p}=0,28411)$. Realidade similar à registrada pelos pescadores de São João de Pirabas (PA), onde 34,0\% dos pescadores vivem com renda mensal inferior a um salário mínimo, 64,0\% com um a dois salários e, 2,0\% de três a quatro salários (BRITO et al., 2015a), realidade também vivenciada pelos pescadores do Rio Grande do Sul, onde 37\% deles obtiveram renda de até um salário mínimo, $52 \%$ superior a um e até três salários e, 11\% superior a três e até quatro salários (GARCEZ; SÁNCHEZ-BOTERO, 2005).

\section{Caracterização da atividade de pesca}

Em relação atividade desenvolvida, foram identificadas oito artes de pesca utilizadas pelos entrevistados em ambas as comunidades: rede de emalhe, rede de arrasto, rede de tapagem, tarrafa, linha de mão, espinhel, matapi e a pesca de mergulho com ou sem visor (Tabela 3), sendo comum a prática de mais de uma delas pelos entrevistados. Não houve uma diferença significativa quanto a frequências de uso das artes de pescas adotadas nas comunidades $\left(\chi^{2}=7,2194, p=0,4064\right)$. Esses petrechos têm sido comumente utilizados por pescadores das ilhas do entorno de Belém 
(SCHALLENBERGER, 2010), a longo do litoral paraense (BRITO et al., 2015a; RAMOS et al., 2015; BRITO et al., 2016a), exceto a pesca de mergulho.

Durante as entrevistas, comumente se conversava com os pescadores, enquanto, os mesmos confeccionavam ou realizavam a manutenção de petrechos de pesca, principalmente de redes de emalhe e tarrafas. Portanto, parte dos artefatos pesqueiros era confeccionada pelos próprios usuários. Os petrechos de pesca também podiam ser adquiridos através da compra ou troca de bens e/ou serviços nas comunidades, sendo eles comumente adaptados para os pesqueiros explorados.

\section{Tabela 3 - Frequências relativa e características dos petrechos de pesca utilizados pelos entrevistados.}

\begin{tabular}{|c|c|c|c|c|c|}
\hline $\begin{array}{l}\text { Área de } \\
\text { estudo }\end{array}$ & Artefato de pesca & $\begin{array}{l}\text { Quant. de } \\
\text { respostas (n) }\end{array}$ & $\begin{array}{l}\text { Freq. } \\
\text { Relativa } \\
(\%)\end{array}$ & $\begin{array}{l}\text { Tamanho da malha ou } \\
\text { numeração do anzol }\end{array}$ & $\begin{array}{c}\text { Tamanho da rede } \\
\text { ou quantidade de } \\
\text { anzóis }\end{array}$ \\
\hline \multirow{8}{*}{ 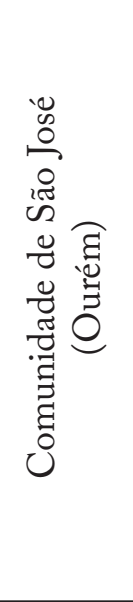 } & Rede de emalhe & 20 & 64,5 & $20,25,30,35,40,50 \mathrm{~mm}$ & $\begin{array}{c}8,10,12,15,20,25 \\
30,50,100 \mathrm{~m}\end{array}$ \\
\hline & Rede de arrasto & 04 & 12,9 & $25,30,40 \mathrm{~mm}$ & $\begin{array}{c}10,20,25,30,50, \\
100 \mathrm{~m}\end{array}$ \\
\hline & Tarrafa & 22 & 71,0 & $20,25,30,35 \mathrm{~mm}$ & $8,12,18,22$ palmos \\
\hline & Linha de mão & 18 & 58,1 & $7,9,12,13,14,15,16,17$ & $2,3,4,5,7$ \\
\hline & Espinhel & 02 & 06,5 & $14,15,16,20$ & $30,50,40,100$ \\
\hline & Tapagem & 01 & 03,2 & - & - \\
\hline & Matapi & 01 & 03,2 & - & - \\
\hline & Mergulho & 03 & 09,7 & - & - \\
\hline \multirow{8}{*}{ 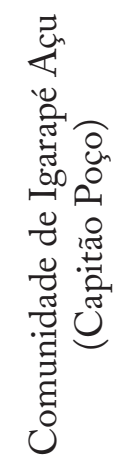 } & Rede de emalhe & 10 & 41,7 & \multirow{8}{*}{$\begin{array}{c}12,25,30,40,50 \\
55,60,65 \mathrm{~mm} \\
30 \mathrm{~mm} \\
25,30 \mathrm{~mm} \\
05,06,08,10,15,18 \\
01,03,05,06,08,10,15 \\
18 \\
-\end{array}$} & \multirow{8}{*}{$\begin{array}{c}\text { 5, 10, 12,15,20 } \\
30,40,50 \mathrm{~m} \\
60 \mathrm{~m} \\
12,15,22 \text { palmos } \\
1 \mathrm{a} 3 \\
\text { 12, 15, 20, 30, } 50 \\
\text { anzóis } \\
- \\
- \\
-\end{array}$} \\
\hline & Rede de arrasto & 01 & 04,2 & & \\
\hline & Tarrafa & 15 & 62,5 & & \\
\hline & Linha de mão & 10 & 41,7 & & \\
\hline & Espinhel & 04 & 16,7 & & \\
\hline & Tapagem & 01 & 04,2 & & \\
\hline & Matapi & 01 & 04,2 & & \\
\hline & Mergulho & 07 & 29,2 & & \\
\hline
\end{tabular}

Fonte: Autores (2015).

A tarrafa foi a principal arte de pesca utilizada nas duas comunidades. $\mathrm{Na}$ comunidade de Igarapé Açu (Capitão Poço) foram registrados três tamanhos (12, 15 e 22 palmos) e apenas dois tamanhos de malhas (25 e $30 \mathrm{~mm}$ ), enquanto para a comunidade de São José (Ourém) foram identificadas tarrafas com quatro tamanhos (8, 12, 18 e 22 palmos) e quatro tamanhos de malhas $(20,25,30$ e $35 \mathrm{~mm})$. O tamanho e as malhas das tarrafas foram similares para ambas as comunidades (Tabela 3). No entanto, o uso desse petrecho pelos pescadores está em desacordo com a legislação, pois o uso de tarrafas de qualquer tipo com malha inferior a $50 \mathrm{~mm}$, em águas interiores, tem sido proibido desde o início da década de 1970 (SUDEPE, 1972).

A tarrafa é um tipo de específico de rede de pesca circular. Ela apresenta pesos distribuídos sobre a extremidade da circunferência de sua malha. Quando lançada pelo pescador, ela se abre 
por completo no ar, antes de cair sobre a água. Ao entrar em contanto com a água, os pesos da extremidade da malha forçam a rede a afundar imediatamente. Caso haja algum tipo de pescado no local onde a rede tocou a água, é muito provável que seja capturado quando a tarrafa se feche, ao ser puxada pelo pescador. Para Nery (1995), esse petrecho apresenta uma forma cônica quando pendurada, mas quando lançada na água, para a captura do pescado, toma a forma de uma grande "saia-rodada", sendo geralmente utilizado para captura de peixes e camarões.

O tamanho da malha utilizada reflete a seletividade da tarrafa, definindo o tamanho do pescado a ser capturado. A dimensão da rede reflete a quantidade de pescado a ser capturado, quanto maior for o tamanho da tarrafa, maior será o diâmetro da área que ela cobrirá quando lançada sobre a água, sendo, portanto, maior a chance de capturar uma quantidade maior de pescado a cada lance. No entanto, seu tamanho deverá se adequar às características do pesqueiro onde comumente será utilizada.

Como esse petrecho de pesca geralmente é confeccionado pelos próprios usuários ou é adquirido nas comunidades, seu tamanho é referido em palmos, ou seja, refletindo quantas palmas de mão de quem a construiu, ela apresenta. Esse tipo de medida em palmos também foi registrado para as tarrafas utilizadas por pescadores do município de Viseu (PA) (RAMOS et al., 2015). Pode-se estimar que cada palmo tem entre 20 e 25 centímetros de comprimento.

A preferência pela tarrafa pode estar relacionada a três fatores: a proximidade do pesqueiro; as dimensões do pesqueiro e às características da tarrafa. Como a tarrafa apresenta menor dimensão que as redes de arrasto e de emalhe torna-se mais fácil de ser levada pelo pescador que tem como pesqueiros o pequeno curso de água próximo do seu local de moradia. Como os igarapés (termo regional que faz referência a rios de pequeno porte) têm dimensões pequenas, tanto em largura como em profundidade, a tarrafa apresenta-se como o recurso possível de ser usado nestes locais. Essas características do petrecho, o torna mais adequado para o uso dos pescadores, além do fato de ter grande eficiência de pesca, por poder ser lançada rapidamente por diversas vezes e por poder ter uma captura maior de peixes em relação à linha de mão.

$\mathrm{O}$ segundo artefato de pesca mais utilizado, nas comunidades, foi a rede de emalhe. $\mathrm{Na}$ comunidade de Igarapé Açu (Capitão Poço), o comprimento das redes variou entre 5 e $50 \mathrm{~m}$ (média $22,75 \mathrm{~m}$ ) e foram registrados oito tamanhos de malhas que variaram entre 12 e $65 \mathrm{~mm}$. Para a comunidade de São José (Ourém), as redes de emalhe variaram entre 8 e 100 m de comprimento (média $30 \mathrm{~m}$ ) e seis tamanhos de malhas eram utilizados, variando entre 20 e $50 \mathrm{~mm}$ (Tabela 3).

A utilização de redes de pequeno porte e de diferentes malhas entre nós variou de acordo com as espécies alvo e locais de pesca. Redes menores, geralmente eram empregadas por pescadores que realizavam a atividade de pesca próxima à comunidade, em pequenos cursos de água, enquanto as redes de tamanhos maiores eram utilizadas em pesqueiros situados no rio principal, Rio Guamá.

As redes de emalhe tem sido o petrecho de pesca mais utilizado por pescadores do estado do Pará tanto em águas interiores (NOGUEIRA et al., 2015) quanto em água costeiras (BRITO; VIANA; 2011; RAMOS et al, 2015; BRITO et al, 2015a; BRITO et al., 2016a). De acordo com Brito e Viana (2011) as redes de emalhe foram a principal arte de pesca utilizada nas colônias de pescadores do nordeste paraense, as mesmas variaram de tamanho entre 35 e $5.000 \mathrm{~m}$ (média $1.193,5 \mathrm{~m}$ ) e malhas entre 20 e $70 \mathrm{~mm}$.

Schallenberger (2010) registrou tamanhos médios de redes que variaram de 95 a $1.267 \mathrm{~m}$ para a pesca de subsistência e de comercialização utilizado por pescadores das ilhas ao redor de Belém, cujo tamanho das malhas variaram de 25 a 90 mm e pescavam sobre áreas do Rio Guamá, 
Baia do Guajará, Baia do Marajó, regiões mais próximas da costa do estado. Isso demonstra que as redes utilizadas em águas continentais têm tamanhos bem inferiores que as utilizadas no litoral do estado. Fato esse também constatado para as redes utilizadas em águas interiores e costeiras do estado do Amapá (CALVACANTE, 2011).

A relação estabelecida entre o tipo do pesqueiro (costeiro ou de águas interiores) e o tamanho do petrecho de pesca usado pode está relacionada aos pesqueiros costeiros terem maiores dimensões, assim, podem demandam o uso de artes de pesca de maior proporção. Os pesqueiros de águas continentais podem ser de menores dimensões, consequentemente demandam o uso de artes de pescas de menor proporção e mais relacionadas com esses ambientes.

A utilização de redes com malhas muito pequenas pode ocasionar danos aos estoques pesqueiros da região, por capturar um quantitativo de peixes de menor porte, que possivelmente não tiveram a chance de se desenvolver totalmente e de se reproduzir na região. Além disso, malhas muitos pequenas podem ocasionar a captura de juvenis de outras espécies da fauna que não seriam o alvo de captura, gerando, portanto, um impacto indesejado para o recurso pesqueiro local.

A linha de mão ou linha e anzol foi o terceiro aparelho de pesca mais utilizado entre os pescadores. A linha de mão utilizada na comunidade de Igarapé Açu (Capitão Poço) era composta por até três anzóis, sendo empregados seis tipos diferentes de anzóis, com numeração variando entre 5 e 18. Na comunidade de São José (Ourém), a linha de mão apresentava de dois a sete anzóis, e eram utilizados até oito tipos de numerações diferentes variando entre 7 e 17 (Tabela 3).

Essa arte de pesca consiste de uma linha principal, de onde se ramificam linhas secundárias, cada qual com um anzol em sua extremidade. A numeração do anzol adotada varia de acordo com o tamanho do pescado a ser capturado. Nery (1995) descreve que as linhas de mão utilizadas por pescadores do salgado paraense eram compostas por um a três anzóis, diferentemente do utilizado na comunidade de São José (Ourém), onde se empregava um quantitativo de até sete anzóis.

Para pescadores do município de Marabá (PA), a linha de mão utilizada era composta de 3 a 10 anzóis de numeração 7, 10 e 16 (NOGUEIRA et al., 2015), similar ao registrado para as comunidades estudadas. Os pescadores de São João de Pirabas (PA) comumente utilizavam de 2 a 5 anzóis de numeração 3 e 4, enquanto, para a captura específica da cavala, utilizavam uma linha de mão com 50 anzóis (BRITO et al., 2015a).

A utilização de espinheis também ocorreu na região. De acordo com Nery (1995), o espinhel é constituído por uma linha mestra de onde partem as linhas de anzóis, podendo ser sustentada a superfície por boias e, ao fundo, por poitas (pedras). A quantidade de anzóis utilizada nos espinheis da comunidade de Igarapé Açu (Capitão Poço) variou entre 12 e 50 anzóis (média 25 anzóis), cujas numerações variaram entre 1 e 18. Na comunidade de São José (Ourém) variou de 30 a 100 anzóis (média 55 anzóis) e cujas numerações foram 14, 15, 16 e 20 (Tabela 3).

O número de anzóis por espinhel utilizado pelos pescadores da região foi bem inferior à quantidade média de anzóis utilizada pelos pescadores das ilhas entorno de Belém, sendo utilizada uma média de 49 a 795 anzóis por artefato, com numeração variando de 1 a 14 (SCHALLENBERGER, 2010). Os pescadores de Colares (PA) utilizavam de 200 a 800 anzóis de numeração 7 a 10 (BRITO et al., 2016a), de São João de Pirabas, de 1.500 e 2.000 anzóis de numeração 7 a 13 (BRITO et al., 2015a), e de Viseu, de 100 e 1.000 anzóis de numeração 7 a 12 (RAMOS et al, 2015).

Esses pescadores do litoral paraense utilizam uma quantidade superior de anzóis quando comparada a registrada para as comunidades estudadas. Fato este, que pode ser reflexo das 
características dos pesqueiros. Boa parte dos pescadores das comunidades de Igarapé Açu (Capitão Poço) e de São José (Ourém) capturam seus pescados em águas interiores, tendo como pesqueiros, os pequenos cursos de água próximos ao local de moradia ou no rio principal. Os pescadores do litoral paraense pescam na região costeira e apresentam áreas de exploração e captura superiores as áreas de águas interiores, por isso, a quantidade de anzóis torna-se maior para aumentar o volume de recursos a ser capturado por unidade de área.

A rede de tapagem foi uma arte de pesca pouco comum para as comunidades estudadas. Essa arte de pesca é uma armadilha, geralmente constituída de uma rede, estendida durante a preamar na foz de pequenos rios ou igarapés que sofrem influência do fluxo e refluxo das marés e, ela é retirada próximo da baixa-mar, quando é feita também a despesca (NERY,1995). Nos pesqueiros do entorno das comunidades, não houve registro da influência das marés, tanto verificado por observação do local, quanto comentado pelos próprios pescadores. Por isso, a tapagem foi pouco utilizada pelos pescadores.

O matapi também foi um artefato pesqueiro pouco utilizado na região, sendo um tipo de armadilha de pesca adotada para capturar camarões e peixes de pequeno porte. A rede de tapagem e o matapi foram artefatos de pesca utilizados por pescadores das ilhas ao redor da capital do estado do Pará (SCHALLENBERGER, 2010), e também no litoral paraense (BRITO; VIANA, 2011), sendo pouco utilizados pelos pescadores das comunidades estudadas (Tabela 3).

A pesca de mergulho foi realizada em ambas as comunidades, sendo realizada tanto para captura de peixes de corte quanto para peixes ornamentais. Esse tipo de pesca também era conhecida como pesca de visor, devido o uso de uma máscara/visor para realização dos mergulhos pelos pescadores, os quais capturavam o pescado com a mão, no caso de espécies ornamentais, ou com o uso de uma fisga, espécie de arpão confeccionados pelos próprios pescadores para capturar os peixes para consumo e/ou venda (Figura 1).

Esse tipo de pescaria geralmente não era realizado em dias de lua cheia, devido o rio ficar iluminado neste período. Nas noites em que não eram de lua cheia, a baixa iluminação da coluna de água facilitava a captura do pescado, pois o uso de lanternas, que auxiliam o deslocamento do pescador dentro da água, também servia para atrair e ofuscar os peixes, facilitando sua captura.

Para os pescadores locais, a pesca de mergulho prejudica os estoques pesqueiros. De acordo com Torres (2007) a pesca com visor é atualmente uma das pescarias mais predatórias em uso na região, sendo mais praticada durante a estação menos chuvosa.

A fisga era composta de duas partes, sendo uma de madeira semelhante ao cabo de espingarda e outra de metal com ponta afiada, como uma lança. A propulsão da ponta de metal era feita por uma borracha de câmara de pneu ou de látex, que era expandida no momento da armação da fisga e liberada no momento da captura do peixe, durante o mergulho realizado pelo pescador.

Esse tipo de pesca com fisga tem sido utilizada em associação com outras artes de pesca também no município de Marabá (PA) (NOGUEIRA et al., 2015), sendo um tipo de pescaria artesanal praticada em água interiores do estado do Pará, geralmente a noite e com auxílio de laterna para localizar peixes como tucunarés e outros ciclídeos presentes em regiões de lagos (ISAAC et al., 2008).

O uso de fisga pelo processo de lambada em águas interiores é proibido desde o início da década de 1970 (SUDEPE, 1972). No entanto, tem sido uma arte de pesca praticada nas comunidades de Igarapé Açu (Capitão Poço) e de São José (Ourém), onde o lançamento da fisga pode ocasionar grandes lesões ao pescado e nem sempre levar a sua captura, mas pode ocasionar a 


\section{Figura 1 - Fisga, petrecho confeccionado pelos pescadores para capturar peixes de corte na pesca de mergulho/visor.}

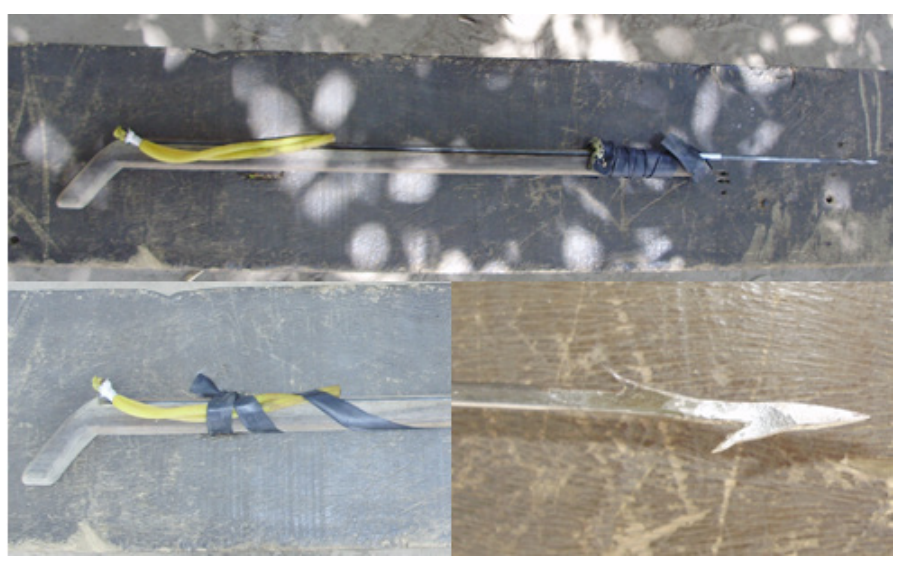

Fonte: Autores (2015).

morte do animal posteriormente. Esse processo, portanto, tem sérios impactos ao recurso pesqueiro local, pois há desperdício de peixes feridos e não capturados, somado aos peixes capturados.

Para a comunidade de Igarapé Açu (Capitão Poço) o tempo médio de chegada ao pesqueiro foi de $6,45 \pm 15,42 \mathrm{~h}$, com tempo médio de pescaria de $54,33 \pm 48,76$ h e frequência média de pescaria de 1,73 $\pm 1,10$ vezes/semana. No entanto, o tempo médio de chegada ao local de pesca, para a comunidade de São José (Ourém), foi inferior a uma hora $(0,80 \pm 0,95 \mathrm{~h})$, com tempo médio de pescaria de 14,44 $\pm 17,07$ h e frequência média de viagens de 1,92 $\pm 1,63$ vezes/semana (Tabela 4), havendo, portanto, uma diferença significativa entre o tempo de chegada no pesqueiro $(\mathrm{U}=220,50, \mathrm{p}=0,0340)$ e o tempo de pescaria $(\mathrm{U}=209,00, \mathrm{p}=0,0057)$ entre as comunidades, no entanto, as frequências de viagens se mostraram similares $(U=337,00, p=0,9424)$.

Os pescadores da comunidade de Igarapé Açu (Capitão Poço) demandam maior tempo para alcançar o pesqueiro do que os pescadores da comunidade de São José (Ourém), pois pescam em regiões mais afastadas dos seus locais de moradia. Por demandarem maior tempo de deslocamento às áreas de pesca, os pescadores da comunidade de Igarapé Açu (Capitão Poço) permanecem mais tempo nos pesqueiros para garantir a captura de pescado. Isto reflete diretamente sobre um número menor de viagens mensais, pois quanto mais longe for o local de pesca, maior será o tempo demandado para pescaria, de forma a se ter uma maior rentabilidade da atividade e, portanto, menor será a frequência de viagens semanais e/ou mensais que realizarão.

Essa questão também foi abordada por Brito et al. (2016a), ao verificarem que quanto maior for o tempo de deslocamento necessário para se atingir os locais de pesca, maior será o tempo que permanecerão na área realizando a pescaria, diminuindo, portanto, a frequência de viagens semanais e/ou mensais.

O tempo de realização da atividade pesqueira variou entre os entrevistados, pois havia pescadores que se deslocavam aos locais de pesca pela manhã, deixavam seu petrecho no pesqueiro pronto para a captura do pescado e, voltavam para comunidade, demandando apenas alguns minutos ou cerca de uma hora para isso. No final do dia, esses pescadores retornavam aos locais de pesca para retirada da sua pequena rede de emalhe, da sua linha de mão simples e/ou do pequeno espinhel deixado na água pela manhã, removiam o pescado capturado e retornavam a comunidade, realizando isso diariamente. 
Outros pescadores se deslocavam diariamente aos pesqueiros próximos da comunidade e ficavam por algumas horas realizando lances com a tarrafa, podendo ou não, associar a pescaria com tarrafas enquanto aguardavam a captura do pescados em redes de emalhe, linhas de mão ou espinheis deixados na água. Outros pescadores iam mais longe, pescando sobre o Rio Guamá e Baia do Guajará, demandando, para isso, alguns dias de pescarias, não realizando viagens diárias, mas apenas semanais ou mensais.

Uma parcela dos pescadores de Viseu (PA) também realizava a atividade pesqueira em área mais próximas da comunidade, por isso, pescavam diariamente, permanecendo no local durante um ciclo de maré da região (maré semi diurna). Enquanto, outros pescadores exerciam, preferencialmente, a atividade por vários dias em áreas mais afastadas de seus locais de moradia, refletindo em frequências de viagem mensais bem menor (RAMOS et al,2015), conforme também registrado para os pescadores das comunidades de Igarapé Açu (Capitão Poço) e São José (Ourém).

Essa realidade também tem sido comum para os pescadores do Rio Grande do Sul, que realizam pescarias diariamente, saindo durante as manhãs para armar os petrechos de pesca nos pesqueiros e retornavam, ao final do dia, para a retirada dos equipamentos. Os pescadores também podiam se deslocar a pesqueiros onde permaneciam durante 2 a 15 dias (GARCEZ; SÁNCHEZ-BOTERO, 2005).

\section{Tabela 4 - Tempo de chegada ao pesqueiro, tempo de pescaria e frequência de viagem dos entrevistados.}

\begin{tabular}{|c|c|c|}
\hline & $\begin{array}{l}\text { Comunidade de Igarapé Açu, } \\
\text { Capitão Poço }(\mathrm{n}=24)\end{array}$ & $\begin{array}{c}\text { Comunidade de São José, } \\
\text { Ourém }(\mathrm{n}=31)\end{array}$ \\
\hline $\begin{array}{c}\text { Tempo mínimo de chegada ao pesqueiro } \\
\text { (horas) }\end{array}$ & 0,12 & 0,08 \\
\hline $\begin{array}{l}\text { Tempo máximo de chegada ao pesqueiro } \\
\text { (horas) }\end{array}$ & 72,0 & 05,0 \\
\hline $\begin{array}{l}\text { Tempo médio de chegada ao pesqueiro } \\
\text { (horas) }\end{array}$ & $6,45 \pm 15,42$ & $0,80 \pm 0,95$ \\
\hline Tempo mínimo de pescaria (horas) & 01,0 & 0,20 \\
\hline Tempo máximo de pescaria (horas) & 192,0 & 60,0 \\
\hline Tempo médio de pescaria (horas) & $54,33 \pm 48,76$ & $14,44 \pm 17,07$ \\
\hline Frequência mínima de viagem (vez/mês) & 01,0 & 01,0 \\
\hline Frequência máxima de viagem (vez/mês) & 20,0 & 24,0 \\
\hline Frequência média de viagem (vez/semana) & $1,73 \pm 1,10$ & $1,92 \pm 1,63$ \\
\hline
\end{tabular}

Fonte: Autores (2015).

Na comunidade de Igarapé Açu (Capitão Poço) foram utilizadas três tipos de embarcações, bote a remo (37,50\%), canoa (16,67\%) e rabeta (45,83\%). Na comunidade de São José (Ourém) duas embarcações foram frequentemente usadas para alcançarem o pesqueiro, sendo o bote a remo $(70,0 \%)$ e a canoa $(30,0 \%)$, nem sempre os pescadores eram proprietários dessas embarcações, sendo muitas vezes emprestadas ou cedidas por parentes ou amigos para realização da pescaria. A frequência do tipo de embarcações utilizadas nas comunidades estudadas foi diferente $(\chi 2=$ $17,3861 ; \mathrm{p}=0,0002)$. 
A utilização desses três tipos de embarcações foi condizente com a realidade dos pesqueiros explorados pela maioria dos entrevistados, sendo os igarapés próximos às comunidades. Essas embarcações também foram as utilizadas por comunidades pesqueiras do município de Colares (PA) (BRITO et al., 2016a) e de Viseu (PA) (RAMOS et al., 2015). Os pescadores de São João de Pirabas (PA) utilizam a canoa e canoa motorizada (rabeta), no entanto, se destaca o uso de embarcações de pequeno a médio porte com motores para alcançar pesqueiros mais distantes da comunidade (BRITO et al., 2015a).

Os pescadores artesanais do nordeste paraense podem utilizar canoa a vela e a remo com tempo de autonomia para 3 dias de pesca ou podem utilizar embarcações de madeira provida de propulsão a motor que podem garantir um tempo de pesca de oito a dez dias (SANTOS et al., 2005). A utilização de embarcações de maior porte e movida a motores proporcionam aos pescadores se deslocarem a maiores distâncias de suas comunidades (BRITO et al., 2015a).

O tipo de embarcação utilizada pelos pescadores tem refletido no tempo que os pescadores levam para alcançar o pesqueiro, bem como no tempo de autonomia pescando. Embarcações motorizadas, como as rabetas poderiam diminuir o tempo demandado para alcançar o pesqueiro, em relação aos que apenas utilizam os botes movido a remo, bem como poderiam contribuir para aumentar o tempo de autonomia pescando, pois alcançando o pesqueiro em menor tempo, restaria um período maior disponível para a pescaria, principalmente por parte dos pescadores que realizavam a atividade diariamente e que permanecem nos pesqueiros durante a pesca.

Conforme as informações fornecidas pelos próprios pescadores e os dados levantados na literatura sobre as espécies de peixes capturados e com ocorrência na região (TORRES, 1994; 2007), merecem destaque, para a comunidade de Igarapé Açu (Capitão Poço), a captura das espécies de corte como aracus (Leporinus spp.), pacus (Myleus sp.), tucunarés (Cichla spp.), surubins (Pseudoplatystoma fasciatum) e piranhas (Serrasalmus spp.), capturadas por mais de $25 \%$ dos entrevistados. Na comunidade de São José (Ourém) mereceu destaque a captura de traíras (Hoplias ssp.), aracus (Leporinus spp.), piranhas (Serrasalmus spp.), pacus (Myleus sp.), jacundás (Crenicichla ssp.), tucunarés (Cichla spp.), capturadas por mais de 19\% dos entrevistados.

$\mathrm{Na}$ comunidade de Igarapé Açu (Capitão Poço) a pesca de peixes ornamentais foi realizada por 37,5\% dos entrevistados ( $\mathrm{n}=9$ ) sendo as principais espécies capturadas o acari bola (Peckoltia oligospila), acari picota (Peckoltia sp.), acari pinima (Leporacanthicus galaxias), acari farovela (Farlowella Cf. smithi), acari canoa velha (Ancistrus sp.), loricaria (Loricaria cataphracta), acari assacu (Pseudacanthicus spinosus) e corredora (Corydoras sp.). Na comunidade de São José (Ourém), apenas um pescador tem realizado a pesca ornamental, capturando banjo (Bunocephalus coracoideus) e corredoras (Corydoras ssp.). A pesca ornamental tem sido bem mais expressiva para o município de Capitão Poço, do que para o município de Ourém. A captura dos peixes ocorre durante a pesca de mergulho com visor, os pescadores mergulham em apneia capturando os peixes com as mãos ou com pequenas redes, denominadas de tarrafinhas.

De acordo com Torres $(1994,2007)$ e Santos e Santos (2005) a pesca artesanal de espécies ornamentais é direcionada à captura de peixes vivos, destinada aos mercados aquariofilistas nacional e internacional, podendo também ser destinada a museus e aquários de exposição pública ou colecionadores. Os pescadores podem encurralar os peixes para serem capturados, sendo armazenados em plástico ou dentro de garrafas pets cortadas em fenda e amarradas à roupa ou ao corpo dos pescadores (TORRES, 2007). 
Os pescadores da comunidade de Igarapé Açu (Capitão Poço) desenvolviam a atividade de pesca, preferencialmente, durante o período menos chuvoso da região Amazônica, considerado como período seco ou verão amazônico, conforme registrado por 70,8\% dos entrevistados, $12,6 \%$ afirmaram pescar durante o período chuvoso, 8,3\% durante o ano todo e, 8,3\% não opinaram quanto a essa questão. $\mathrm{O}$ mesmo foi registrado para a comunidade de São José (Ourém) onde $61,3 \%$ dos entrevistados desenvolviam a atividade de pesca preferencialmente durante o período menos chuvoso, 29,0\% afirmaram pescar durante o ano todo, 6,5\% durante o período chuvoso e, $3,2 \%$ não opinaram sobre essa questão, não havendo uma preferência sazonal diferenciada entre as comunidades $\left(\chi^{2}=3,6206, p=0,1636\right)$, mas a pesca tem sido preferencialmente realizada durante o período menos chuvoso da região.

A redução das chuvas, durante o período seco, proporciona a redução do nível de água do rio Guamá e seus afluentes, juntamente com a redução da agitação da coluna de água e da turbidez da água, o que tem facilitado a captura do pescado, conforme retratavam os pescadores. Durante o período chuvoso, ocorre o inverso, o nível de água sobe, aumentando a agitação da coluna de água e, consequentemente, a turbidez dela, dificultando a captura do pescado na região devido à redução da visibilidade e aumento considerável do volume de água.

Quanto ao número de pessoas pescando, 41,7\% dos pescadores da comunidade de Igarapé Açu (Capitão Poço) afirmaram que o número de pessoas pescando tem aumentando nos últimos anos, para 33,3\% continuou o mesmo e para 25,0\%, diminuiu. Para a comunidade de São José (Ourém), 61,3\% dos entrevistados afirmaram que o número de pescados nos locais de pesca tem aumentado, enquanto 25,8\% afirmaram continuar o mesmo e, 12,9\% afirmaram ter diminuído. Isso reflete que a dinâmica dos pescadores pode variar de acordo com os pesqueiros. Em determinados locais de pesca, a escassez do recurso pesqueiro força os pescadores a se deslocarem para outras regiões, onde o recurso possa ser mais abundante, diminuindo, portanto, o número de pescadores em determinados pesqueiros e aumentando em outros, conforme os relatos fornecidos pelos próprios pescadores.

O aumento do número de pessoas pescando na região, nos últimos anos, pode estar contribuindo para diminuição dos cardumes explorados nos pesqueiros mais próximos às comunidades, pois o aumento do volume de pescado capturado não favorece a renovação dos estoques, consequentemente o pescado capturado torna-se cada vez menor ou mais escasso. Isso se confirma pelos próprios entrevistados ao afirmarem que o tamanho dos peixes capturados tem diminuído nos últimos anos.

Para 50,0\% dos pescadores da comunidade de Igarapé Açu (Capitão Poço), o tamanho do pescado tem diminuindo nos últimos anos; para 45,8\% dos pescadores o pescado continua do mesmo tamanho e, apenas 4,2\% afirmaram que o tamanho do pescado tem aumentado. $\mathrm{O}$ mesmo tem sido registrado pelos pescadores de São José (Ourém), onde 58,1\% deles afirmaram que o pescado tem diminuído de tamanho, 29,9\% que tem continuado o mesmo e, para 12,9\% tem aumentado.

A diminuição da produção por consequência da escassez de pescado ou de seu tamanho tem refletido na necessidade do pescador ter que se deslocar para outras áreas de pesca em busca do recurso. Isso foi confirmado por $61,3 \%$ dos entrevistados da comunidade de São José (Ourém), enquanto, os demais pescadores (38,7\%) permaneciam pescando nos mesmos locais de pesca. Para os pescadores da comunidade de Igarapé Açu (Capitão Poço), metade deles teve que se deslocar para outros pesqueiros em busca de pescado, enquanto a outra metade, ainda permanecia pescando nos mesmos locais de pesca. 
Para garantir a manutenção dos estoques pesqueiros, os entrevistados destacaram cinco ações principais que deveriam ser adotadas: (1) recuperação dos estoques pesqueiros com a interrupção da pesca durante a reprodução das espécies, elaborando, assim, um período de defeso; (2) maior gestão e fiscalização dos órgãos competentes quanto às questões da pesca; (3) preservação do ambiente, através da conservação do rio e mata ciliar; (4) proibição da pesca predatória como a pesca de mergulho e a pesca de arrasto; (5) desenvolvimento da criação de peixes na região, podendo um mesmo pescador ter informado mais de uma ação (Tabela 5).

\section{Tabela 5 - Principais ações listadas pelos entrevistados para garantir os recursos pesqueiros na região.}

\begin{tabular}{ccccc}
\hline \multirow{2}{*}{$\begin{array}{c}\text { Ações para garantir os estoques } \\
\text { pesqueiros }\end{array}$} & \multicolumn{2}{c}{$\begin{array}{c}\text { Comunidade de Igarapé Açu } \\
\text { (Capitão Poço) }\end{array}$} & \multicolumn{2}{c}{$\begin{array}{c}\text { Comunidade de São José } \\
\text { (Ourém) }\end{array}$} \\
\cline { 2 - 5 } & $\begin{array}{c}\text { Quant. de } \\
\text { respostas (n) }\end{array}$ & $\begin{array}{c}\text { Freq. } \\
\text { Relativa } \\
(\%)\end{array}$ & $\begin{array}{c}\text { Quant. de } \\
\text { respostas } \\
(\mathrm{n}) *\end{array}$ & $\begin{array}{c}\text { Freq. } \\
\text { Relativa } \\
(\%)\end{array}$ \\
\hline $\begin{array}{c}\text { Criação de peixes } \\
\text { Proibição da pesca predatória } \\
\text { (arrasto e visor) }\end{array}$ & 01 & 04,2 & 01 & 02,8 \\
$\begin{array}{c}\text { Gestão e fiscalização da pesca } \\
\text { Reposição dos estoques (período de } \\
\text { defeso) }\end{array}$ & 05 & 20,8 & 17 & 48,6 \\
$\begin{array}{c}\text { Conservação do ambiente (rio e } \\
\text { vegetação) }\end{array}$ & 03 & 11,5 & 03 & 08,6 \\
\hline Total & 04 & 45,8 & 05 & 14,3 \\
\hline
\end{tabular}

*pescadores optaram por mais de uma ação.

Fonte: Autores (2015).

A reposição dos estoques pesqueiros da região poderá ser assegurada pela determinação do período de defeso, possibilitando que, durante a época de reprodução das espécies, as mesmas não sejam capturadas. Durante esse período, os pescadores poderiam receber subsídio do governo para garantir seu sustento na época em que não poderão exercer a atividade de pesca. No entanto, para que isso possa ser uma realidade da região será necessária a organização social e política dessa classe, seja em associação ou colônia de pescadores, de forma que sejam assegurados seus direitos, conforme legislação vigente.

Faz-se também necessária uma maior fiscalização dos órgãos gestores em relação à atividade de pesca que tem sido realizada na região, que possa impedir que a mesma seja realizada durante o defeso ou que impeça as modalidades de pesca predatória. A presença de uma associação ou colônia de pescadores local poderia contribuir com a orientação das comunidades pesqueiras quanto a essas questões e poderia, também, contribuir com a fiscalização da atividade.

A pesca de arrasto é bastante predatória, pois não é uma arte seletiva, capturando diversas espécies que muitas vezes nem são consumidas ou comercializadas, bem como são capturados espécimes de diferentes tamanhos, prejudicando os estoques da ictiofauna local. A pesca com visor também tem sido predatória conforme apontado por Torres (2007), pois o número de pescadores realizando essa pescaria cresceu, aumentando, o esforço de pesca sobre os recursos que atualmente tem se tornado bastante escasso na região. Além disso, uso de fisga pelo processo de lambada é uma prática predatória e proibida, mas que ainda tem sido praticada na região, 
devido à falta de fiscalização da atividade pesqueira. Essa situação também tem acarretado o uso de redes de pesca com malhas pequenas e com baixa seletividade, aumentando o processo de predação dos estoques pesqueiros da região.

Torres (2007) registrou alguns problemas no município de Ourém como perda da cobertura vegetal em zonas ripárias e consequente assoreamento de rios e igarapés da região, bem como alterações nas características físicas e químicas da água em alguns pontos dos cursos de água. Outros problemas verificados pelo autor foram relativos ao acúmulo de lixo urbano no leito dos rios, resíduos de mandioca extraídos da fabricação de farinha, restos das madeiras e despejos da lavagem de seixo, corroborando com a necessidade de conservação do ambiente para se garantir o recurso pesqueiro na região. Todos esses problemas têm consequências diretas sobre os ambientes aquáticos que podem estar favorecendo a diminuição dos estoques pesqueiros na área de estudo.

A aquicultura poderia ser uma atividade alternativa a ser implantada nas propriedades dos pescadores para assegurar uma fonte de pescado e garantir o sustento das famílias. Isso porque, as comunidades estudadas desenvolvem cultivos agrícolas e pecuários na região como fonte principal de renda, sendo a pesca considera uma atividade secundária de sustento.

Em comunidades do município de Capitão Poço (PA), a prática da piscicultura tem sido uma realidade, sendo uma atividade recentemente desenvolvida pelos produtores da região, que ainda necessitam de capacitação técnica para melhorar o desempenho da produção. A aquicultura garante a subsistência, ao disponibilizar à família do produtor uma alimentação a base de pescado, bem como também contribui como fonte de complementação da renda familiar (BRITO et al., 2017).

\section{Conclusão}

A pesca desenvolvida pelas comunidades rurais estudadas do nordeste paraense tem sido desenvolvida para subsistência familiar e como forma de inserir uma fonte de proteína animal na dieta das comunidades. O estudo demonstrou que a pesca foi realizada por pessoas envolvidas mais com atividades agrícolas do que propriamente pesqueiras, uma realidade oposta da pesca desenvolvida por comunidades localizadas no litoral do estado. Os petrechos de pesca utilizados foram relativamente simples, em sua maioria, confeccionados pelos próprios usuários, ou comprados no comércio local, sendo comumente adaptados para os pesqueiros os quais exploravam. Os entrevistados também demonstraram ter consciência em relação à exploração de forma desordenada da pesca, pontuando os principais problemas como a falta de gestão e fiscalização da atividade e a necessidade de um período de defeso como formas de garantir o recurso pesqueiro às gerações futuras.

\section{Referências}

AYRES, M.; AYRES JÚNIOR, M.; AYRES, D. L.; SANTOS, A. S. dos. BioEstat 5.0: aplicações estatísticas nas áreas das Ciências Biológicas e Médicas. Belém: MCT/IDSM/CNPq, 2007. 364 p.

BAILEY, K. D. Methods of social research. New York: McMillian, 1982. 553 p.

BARRETO, R. C. S. Políticas Públicas e o Desenvolvimento Rural Sustentável no Estado do

Ceará: Estudo de Caso. 2004. 77 f. Dissertação (Mestrado em Economia Rural) - Universidade Federal do Ceará, Fortaleza. 2004. 
BARTHEM, R. B.; FABRÉ, N. N. Biologia e diversidade dos recursos pesqueiros da Amazônia. In: RUFFINO, M. L. (Org.). A pesca e os recursos pesqueiros na Amazônia Brasileira. Manaus: IBAMA/Pró-Varzea, 2003. p. 11-55.

BRITO, T. P.; OLIVEIRA, A. N. D.; SILVA, D. A. C.; ROCHA, J. A. S. Caracterização socioeconômica e tecnológica da atividade de pesca desenvolvida em São João de Pirabas Pará - Brasil. Ambiência, Guarapuava, v.11, n. 3, 2015a.

BRITO, T.P.; OLIVEIRA, A. N. D.; SILVA, D. A. C.; ROCHA, J. A. S. Conhecimento ecológico e captura incidental de tartarugas marinhas em São João de Pirabas, Pará, Brasil. Biotemas, Florianópolis, v.28, n. 3, p.159 - 175, 2015b.

BRITO, T.P.; KLEN, A. C.; DA SILVA,J. F.; ALVES, M. S. Avaliação socioeconômica e a percepção ambiental dos moradores de Mãe do Rio - Pará - Brasil. Conexões: Ciência e Tecnologia, Fortaleza, v. 9, n. 3, p. 23-33, 2015c.

BRITO, T. P.; SANTOS, A. T. S.; QUINTAIROS, R. R. D.; TORRES, M. F. Aspectos socioeconômicos dos aquicultores do município de Capitão Poço - Pará - Brasil. Revista Ambiência, Guarapuava, v. 14, n. 1, p. 09-25, 2018.

BRITO, T.P.; SANTOS, A.T. S.; QUINTAIROS, R. R. D.; COSTA, L. C. O. Aspectos tecnológicos da piscicultura do município de Capitão Poço, Pará, Brasil. Biota Amazônia, Macapá,v. 7, n. 1, p.17-25, 2017.

BRITO,T.P.; VIANA,A.P.Descrição da pesca artesanal em comunidades do litoral do estado do Pará, região Norte - Brasil. In: CONGRESSO BRASILEIRO DE ENGENHARIA DE PESCA, 17, 2011, Belém. Resumos... Belém: AEP. 2011. Versão eletrônica.

BRITO, T. P. O conhecimento ecológico local e a interação de botos com a pesca no litoral do estado do Pará, região Norte - Brasil. Biotemas, Florianópolis, v.25, n. 4, p. 259-277, 2012.

BRITO, T. P.; LIMA, A. L. R.; SENA, C. S. O.; SANTOS, G. B. A pesca artesanal e o conhecimento ecológico sobre peixes-boi (ordem Sirenia) na Ilha de Colares - Pará região Norte - Brasil. Revista Ouricuri, Paulo Afonso, v. 6, n. 1, p. 027-049, 2016a.

BRITO, T. P.; LIMA, E. B. S.; ROSA, J. C. G. S. Avaliação do consumo de quelônios no município de Castanhal - Pará - Brasil. Revista Revista Ouricuri, Paulo Afonso, v. 6, n. 1, p. 71-103, 2016 b.

CAVALCANTE, R. E. S. Caracterização da pesca artesanal exercida pelos pescadores cadastrados na colônia Z-3 do município de Oiapoque-Amapá, Brasil. 2011. 58 f. Trabalho de Conclusão de Curso (Bacharelado em Engenharia de Pesca) - Universidade do Estado do Amapá, Macapá. 2011.

COSTA, D. D.; SILVA, E. R.; BARBOSA, T. C. Caracterização socioeconômica e ambiental dos moradores da comunidade São Pedro, município de Concórdia do Pará, nordeste do estado do Pará. 2013. 22 p. Trabalho de Conclusão de Curso (Técnico em Meio Ambiente) Instituto Federal do Pará, Castanhal. 2013.

BRITO, T. P., COSTA, L. C. O. 
CRUZ NETO, O. O trabalho de campo como descoberta e criação. In: Minayo, M. C. S.; Deslandes, S. F.; Cruz Neto, O.; Gomes, R. (org). Pesquisa social: teoria, método e criatividade. Petrópolis: Vozes, 1994. p. 51-66.

DI CIOMMO, R. C. Maternidade e Atividade Profissional. 1990. 257 f. Dissertação (Mestrado em Sociologia) - Universidade Estadual Paulista, Araraquara. 1990.

DI CIOMMO, R. C. Ecofeminismo e Educação Ambiental. Uberaba: Universidade de Uberaba / Conesul, 1999. 264 p.

DI CIOMMO, R. C. Pescadoras e pescadores: a questão da equidade de gênero em uma reserva extrativista marinha. Ambiente e Sociedade, Campinas, v. 10, n. 1, p. 151-163, 2007.

FREITAS, C. E. DE C.; RIVAS, A. A. F. A pesca e os recursos pesqueiros na Amazônia Ocidental. Ciência \& Cultura, Campinas, v. 58, n. 3, p. 30-32, 2006.

INSTITUTO BRASILEIRO DO MEIO AMBIENTE E DOS RECURSOS NATURAIS RENOVÁVEIS (IBAMA). Estatística de pesca 2006 Brasil: Grandes regiões e unidades da federação. Brasília: MMA/IBAMA, 2008. 174 p.

INSTITUTO BRASILEIRO DE GEOGRAFIA E ESTATÍSTICA (IBGE). Dados do Censo 2010. Diário Oficial da União do dia 04/11/2010: Brasília. 2010. <http://www. censo2010.ibge.gov. br/dados_divulgados/index.php?uf=15>. 01 Jun 2014.

GARCEZ, D. S.; SÁNCHEZ-BOTERO, J. I. Comunidades de pescadores artesanais no estado do Rio Grande do Sul. Revista Atlântica, Rio Grande, v. 27, n. 1, p. 17-29, 2005.

ISAAC, V. J.; ESPÍRITO SANTO, R.; ALMEIDA, M. C.; ALMEIDA, O.; ROMAN, A. P.; NUNES, L. Diagnóstico, tendência, potencial e política pública para o desenvolvimento do setor pesqueiro artesanal. In: SEPAq - SECRETARIA DE ESTADO DE PESCA E AQUICULTURA. Diagnóstico da Pesca e da Aquicultura do Estado do Pará. Belém: SEPAq, v. 2, 155 p. 2008.

LUDKE, M. ANDRÉ, M. E. D. A. Pesquisa em educação: abordagens qualitativas. São Paulo: EPU, 1986. 99 p.

MANESCHY,M.C.A mulher está se afastando da pesca? Continuidade e mudança no papel da mulher na manutenção doméstica entre famílias de pescadores no litoral do Pará. Boletim do Museu Paraense Emilio Goeldi: Antropologia, Belém, v. 11, n. 2, p. 145-166, 1995.

MARTORANO, L. G.; PERREIRA, L. C.; CÉZAR, E. G. M.; PEREIRA, I. C. B. Estudos climáticos do estado do Pará, classificação climática (Kóppen) e deficiência hídrica (Thornthwhite, Mather). Belém: SUDAM/EMBRAPA/SNLCS, 1993. 53p.

MERGULHÃO, M. C.; VASAKI, B. N. G. Educando para a conservação da natureza: sugestões de atividades em educação ambiental. São Paulo: EDUC, 1998. 139 p.

NERY, A. da C. Traços da tecnologia pesqueira de uma área tradicional da Amazônia - Zona do 
Salgado - Pará. Boletim do Museu Paraense Emilio Goeldi, Belém, v. 11, n. 2, p. 199-293, 1995.

NOGUEIRA, C. M. A Divisão Sexual Do Trabalho No Setor Portuário. Serviço Social e Sociedade, São Paulo, n. 111, p. 509-528, 2012.

NOGUEIRA, J. W. M.; RODRIGUES, L. S.; SANTOS, M. J.; BRITO, T. P. A pesca artesanal desenvolvida em Marabá - Pará - Brasil. In: CONGRESSO BRASILEIRO DE ENGENHARIA DE PESCA, 19, 2015, São Luis. Anais... São Luis: Associação Brasileira dos Engenheiros de Pesca / Universidade Federal do Maranhão, 2015. 5 p. Versão eletrônica.

OLIVEIRA, M. F. S.; SANTOS, M. J.; SILVA NETO, A. M.; RAMOS, L. A. S.; TRINDADE, H. M.; BRITO, T. P. Os atores envolvidos na pesca artesanal de Viseu - PA - Brasil. In: SIMPÓSIO DE ESTUDOS E PESQUISAS EM CIÊNCIAS AMBIENTAIS NA AMAZÔNIA, 4, 2015, Belém. Anais... Belém: Universidade do Estado do Pará, 2015, v. 3, p. 42-52. Versão eletrônica. RAMIRES, M.; BARRELLA, W.; ESTEVES, M. Caracterização da pesca artesanal e o conhecimento pesqueiro local no Vale do Ribeira e Litoral Sul de São Paulo. Revista Ceciliana, Santos, v. 4, n. 1, p. 37-43, 2012.

RAMOS, L. A. S.; SANTOS, M. J.; OLIVEIRA, M. F. S.; SANTOS, G. B.; BRITO, T. P. Aspectos tecnológicos da pesca artesanal desenvolvida em Viseu - Pará - Brasil. In: SIMPÓSIO DE ESTUDOS E PESQUISAS EM CIÊNCIAS AMBIENTAIS NA AMAZÔNIA, 4, 2015, Belém. Anais... Belém: Universidade do Estado do Pará, 2015. p. 507-516. Versão eletrônica.

RUFFINO, M. L.; SILVA JÚNIOR, U. L.; SOARES, E. C.; SILVA, C. O.; BARTHEM, R.; BATISTA, V.; ISAAC, V.; FONSECA, S.; PINTO, W. Estatística pesqueira do Amazonas e Pará 2002. Manaus: ProVárzea/IBAMA, 2005. 84 p.

RUFFINO, M. L.; SOARES, E. C.; SILVA, C. O.; BARTHEM, R.; BATISTA, V.; STUPINAN, G.; PINTO, W. Estatística pesqueira do Amazonas e Pará - 2003. Manaus: ProVárzea/ IBAMA, 2006. 80 p.

SANTOS, F. J. C.; DA COSTA JÚNIOR, J. G.; VILAÇA, S. L. C. Caracterização da piscicultura no município de Castanhal, Pará - Brasil. 2014. 65 f. Trabalho de Conclusão de Curso (Tecnologia em Aquicultura) - Instituto Federal do Pará, Castanhal. 2014.

SANTOS, G. M.; SANTOS, A. C. M. Sustentabilidade da pesca na Amazônia. Estudos Avançados, São Paulo, v. 19, n. 54, p. 165-182, 2005.

SANTOS, M. A. S. A cadeia produtiva da pesca artesanal no estado do Pará: estudo de caso no nordeste paraense. Amazônia: Ciência \& Desenvolvimento, Belém, v.1, n.1, p. 61-81, 2005.

SANTOS, M. A. S.; GUERREIRO FILHO, M. C. S.; NEVES, P. R. S.; DE AGUILAR, C. G. G. Análise socioeconômica da pesca artesanal no Nordeste Paraense. In: CONGRESSO DA SOBER, 43. 2005. Resumos... Ribeirão Preto: Sociedade Brasileira de Economia e Sociologia Rural. 2005. Versão eletrônica.

BRITO, T. P., COSTA, L. C. O. 
SCHALLENBERGER, B. H. A atividade pesqueira nas Ilhas do entorno de Belém. 2010. 151 p. Dissertação (Mestrado Ecologia Aquática e Pesca) - Universidade Federal do Pará, Belém. 2010. SUDEPE - SUPERINTENDÊNCIA DO DESENVOLVIMENTO DA PESCA. Portaria 466, de 08 de novembro de 1972. Diário Oficial da União. Brasília, 1972.

SILVA, M. DA C.; OLIVEIRA, A. S.; NUNES, G. Q. Caracterização socioeconômica da pesca artesanal no município de conceição do Araguaia, estado do Pará. Amazônia: Ciência \& Desenvolvimento, Belém, v. 2, n. 4, p. 37-51, 2007.

SOUZA, M. R. Etnoconhecimento caiçara e uso de recursos pesqueiros por pescadores artesanais e esportivos no Vale Ribeira. 2004. 102 f. Dissertação (Mestrado em Ecologia de Agroecossistemas) - Universidade de São Paulo, Piracicaba. 2004.

TORRES, M. F. Estudo preliminar da pesca artesanal de peixes ornamentais no município de Ourém, Pará. 1994. 22 f. Trabalho de Conclusão de Curso (Bacharelado em Biologia) Universidade Federal do Pará, Belém. 1994.

TORRES, M. F. A pesca ornamental na bacia do rio Guamá: sustentabilidade e perspectivas ao manejo. 2007. 287 f. Tese (Doutorado em Desenvolvimento Sustentável do Trópico Úmido) - Universidade Federal do Pará, Belém. 2007.

VERDEJO, M. E. Diagnóstico Rural Participativo: Guia Prático. 3. ed. Brasília - DF: MDA/ Secretaria de Agricultura Familiar - SAF, 2010. 62 p. 